\title{
Docência na universidade, cultura e avaliação institucional: saberes silenciados em questão
}

\author{
Maria Isabel da Cunha
}

Universidade do Vale do Rio dos Sinos, Programa de Pós-Graduação em Educação

\section{O problema}

As análises realizadas sobre a docência universitária encaminham, geralmente, para reflexões sistemáticas sobre a constituição da profissão docente nesse grau de ensino, saberes e competências próprias do professor e inovações protagonizadas nos espaços acadêmicos. Essas preocupações têm como meta subsidiar a compreensão da prática pedagógica dos professores e fazer avançar um conhecimento especializado sobre sua formação.

A formação do professor universitário tem sido entendida, por força da tradição e ratificada pela legislação, como atinente quase que exclusivamente aos saberes do conteúdo de ensino. Espera-se que o professor seja, cada vez mais, um especialista em sua área, tendo-se apropriado, com o concurso da pósgraduação stricto sensu, do conhecimento legitimado academicamente no seu campo científico. O domínio do conteúdo, por sua vez, deve ser alicerçado nas atividades de pesquisa que garantam a capacidade potencial de produção de conhecimento.

O prestígio do professor universitário no âmbito acadêmico, ainda que essa condição possa variar em intensidade segundo a origem de área, alicerça-se, basicamente, nas atividades de pesquisa, incluindo as publicações e participações em eventos qualificados. O professor é, ainda, valorizado pela atividade de orientação de dissertações e teses que realiza, bem como pela participação em bancas e processos ligados à pós-graduação. Consultorias e cargos na administração universitária também se constituem em um valor profissional.

O ensino, especialmente o ensino de graduação, é entendido como decorrência das demais atividades, assumindo uma forma naturalizada de exercício. A naturalização da docência refere-se à manutenção dos processos de reprodução cultural como base da docência, ou seja, o professor ensina a partir da sua experiência como aluno, inspirado em seus antigos professores.

Muitas são as pesquisas que detectaram essa espiral reprodutiva de formação. Sendo a docência uma ação humana, ela é também histórica e cultural, ou seja, está imbricada numa teia de significados que constituem os sujeitos. Como afirma Larrosa (1998), "não há experiência humana não mediada pela forma e a cultura. É justamente nesse conjunto de esquemas 
de mediação e de um conjunto de formas, que se delimitam e dão perfis às coisas, às pessoas e a nós mesmos” (p. 59). Nessa perspectiva, é possível identificar na docência o perfil de uma ação cultural, presente na trajetória da maioria das pessoas, fazendo parte do senso comum, como representação social.

Essa condição, entendida, num primeiro momento, como ligada com mais intensidade aos processos individuais, deriva também da construção de uma inserção identitária dos sujeitos na instituição escolar e acadêmica. Sugere a exploração do conceito de identidade institucional, expressão utilizada por Remedi (2004), quando faz referência "às formas como os sujeitos constroem sua subjetividade em determinados espaços vividos, como sentido de pertença coletiva, com significados compartidos, memória coletiva, mitos e crenças fundacionais, linguagens, estilos de vida e sistemas de comportamento" (p. 34). Há uma mescla de fatores em que a subjetivação dos referentes simbólicos e imaginários das instituições retoma os elementos já construídos na própria trajetória dos sujeitos.

Todos os professores foram alunos de outros professores e viveram as mediações de valores e práticas pedagógicas. Absorveram visões de mundo, concepções epistemológicas, posições políticas e experiências didáticas. Através delas foram se formando e organizando, de forma consciente ou não, seus esquemas cognitivos e afetivos, que acabam dando suporte para a sua futura docência.

Intervir nesse processo de naturalização profissional exige uma energia sistematizada de reflexão, baseada na desconstrução da experiência. Os sujeitos professores só alteram suas práticas quando são capazes de refletir sobre si e sobre sua formação. A desconstrução é um processo em que se pode decompor a história de vida, identificando as mediações fundamentais, para recompor uma ação educativa e profissional conseqüente e fundamentada. Exige dos homens, como explicita Freire (1976), "uma 'arqueologia' da consciência, através de cujo esforço eles podem, em certo sentido, refazer caminhos" ( $p$. 100) que levam a processos emancipatórios.
Talvez esse seja o sentido principal da formação de professores, seja ela inicial ou continuada. No caso dos docentes universitários, quanto mais os processos de ensinar e aprender não são objeto de formação inicial, mais intensa parece ser a reprodução cultural. Certamente são eles mais vulneráveis, também, às influências externas, especialmente das políticas públicas, quando elas impõem padrões de qualidade aleatórios, interferindo na identidade individual e na identidade institucional. A carência do hábito de uma reflexividade sustentada por bases teóricas deixa os docentes do ensino superior mais suscetíveis aos modelos externos, capazes de imprimir projetos pedagógicos nem sempre explicitados e, muito menos, discutidos.

Esses são os pressupostos que estimularam uma ação investigativa sobre os impactos do modelo avaliativo, imposto pelo Ministério da Educação (MEC) ao ensino superior, na segunda metade da década de 1990, sobre a docência universitária.

A preocupação com o ensino superior, especialmente com a qualidade de seus resultados, emergiu fortemente nesse período. Os órgãos internacionais de financiamento, expressando uma ideologia dominante no mundo globalizado, dedicaram uma especial atenção à relação educação e desenvolvimento econômico, com visível desvantagem para os países dependentes.

$$
\text { Borja (2003, p. 38) explicita: }
$$

enquanto a globalização é um fenômeno múltiplo que prevê a internacionalização e interdependência das economias nacionais, o globalismo é uma construção ideológica que pretende explicar e justificar a globalização com todos seus abusos, excessos, assimetrias e perversões e estendêla pelo mundo com uma clara estratégia dos países industriais para conquistar mercados, acrescentar laços de dependência externa e aprofundar a clássica divisão internacional do trabalho, além de exercer dominação ideológica, política, econômica, científica e tecnológica.

O panorama internacional vem tendo fortes repercussões em nosso país, que, a partir de 1995, acen- 
tuou o caráter neoliberal das políticas governamentais, incluindo o campo da educação, ávido de beneficiar-se de financiamentos externos. Na própria lei n. 9.394/96, as Diretrizes e Bases da Educação Nacional (LDBEN) refletiram os novos ventos que sopravam numa direção até então contestada pela sociedade civil organizada.

A questão da qualidade de ensino tem sido, então, objeto de disputa ideológica. Para alguns, representa a possibilidade de um sistema que atenda as exigências do mundo produtivo, respeitando a estrutura de poder que articula os países ricos com os dependentes. Para outros, significa o desenvolvimento de uma cultura crítica e fundamentada, capaz de acenar com uma condição emancipatória. A primeira tem a competitividade como êmulo e a segunda aposta na solidariedade como possibilidade.

No âmbito dos sistemas de ensino, como afirma Martins (2002), "o discurso que tem fundamentado a necessidade de reformas educacionais contemporâneas vem fazendo apelo à excelência, eficácia e eficiência, à competitividade e outros aspectos da racionalidade econômica" (p. 271). Percebe-se a invariável disposição de que a melhoria dos sistemas educativos esteja atrelada aos indicadores de produtividade. Tal posição é decorrente das mudanças da concepção de Estado, que assume, cada vez mais, uma função regulatória, através dos mecanismos de avaliação.

No contexto da expansão do ensino superior brasileiro, as políticas governamentais optaram por uma estratégia de incentivo à iniciativa privada, favorecendo a ampliação significativa do número de universidades, centros universitários e faculdades isoladas. A par e passo com essas medidas, foi implantado um sistema de avaliação externa alicerçado na perspectiva da universalização do padrão de qualidade e no espaço concorrencial que se estabelece entre os envolvidos. Nesses processos foi dado especial destaque ao Exame Nacional de Cursos, que ficou conhecido como "provão", instituído pela lei n. 9.131, de 24 de novembro de 1995. Nele, como ressaltam Lüdke e Moreira (2002), "a atenção se desloca da avaliação institucional para a avaliação individual, ou seja, para o desempenho pessoal de cada estudante" (p. 59). Essa condição estabelece-se na contramão dos esforços até então realizados pelas universidades, inspirados no Programa de Avaliação Institucional das Universidades Brasileiras (PAIUB). ${ }^{1}$ Como repercussão dessa medida, tem-se um esvaziamento das iniciativas mencionadas, no sentido de um processo conseqüente de avaliação educativa, substituído por um mecanismo parcial de aferição das aprendizagens cognitivas dos estudantes. E, como bem lembra Dias Sobrinho (2000), medir é diferente de avaliar, sendo apenas parte de um processo muito mais amplo. Reduzir a avaliação à aplicação de uma prova é reforçar uma visão mecanicista e simplificadora, constituída como uma tecnificação da formação. É como se fosse possível estabelecer uma relação causal entre o sucesso numa prova e o desempenho profissional, assim como ligar, linearmente, as aprendizagens realizadas pelos estudantes durante um curso e a capacidade de responder a um instrumento pontual de avaliação. A defesa desse pressuposto significaria entender a formação numa perspectiva estreita, ligada ao domínio de um conhecimento que, segundo o autor, "não seria, dentro da concepção tecnicista, algo incorporado às dimensões pessoais do indivíduo, e sim aquilo que o aluno consegue demonstrar mais e melhor do que os outros" (p. 137). Há o deslocamento de um pressuposto formativo de avaliação para um modelo tecnológico, que, de acordo com House (1997), se assenta na perspectiva da produção.

Ainda que, no contexto da avaliação, outros procedimentos tivessem sido anunciados e realizados, a ênfase na publicização dos resultados do "provão", mobilizando a mídia nacional, tornou esse mecanismo legitimado ante a opinião pública. O MEC, nesse período, implementou um aparato sem precedentes

1 Programa gestado e desenvolvido nas instituições brasileiras de ensino superior, com apoio oficial do MEC, na primeira metade da década de 1990. Propunha a auto-avaliação como ponto de partida e assumia critérios de avaliação que reconheciam peculiaridades e culturas, numa perspectiva participativa. 
para a sua realização, e atribuiu ao processo avaliativo a condição de carro-chefe de suas políticas para o ensino superior. Explicitou claramente uma perspectiva tecnológica da avaliação, que se assume com um processo imparcial, neutro e, por esses atributos, insuspeito. Para Dias Sobrinho (2000, p. 140):

erigindo em universais os interesses individuais e em consensuais o que, em realidade, são dissensos e pluralidade de sentidos e valores, as avaliações tecnológicas apresentam-se como indiscutíveis, fundando sua fidedignidade na operação de instrumentos e metodologias precisas, que legitimam a dominação e o controle da realidade analisada.

Toma-se como pressuposto a universalidade de espaços e territórios como se a situação das instituições de ensino superior e dos estudantes fossem as mesmas. Valida-se um instrumento como capaz de definir qualidade, independente do contexto ou de uma escala valorativa de critérios e referências. Nesse sentido, é um processo discriminador, porque toma como iguais os diferentes.

Como a implantação da avaliação utilizando o instrumento do "provão" foi gradativa, a universidade não produziu um processo reflexivo - quer de adesão, quer de resistência - de forma impactante. No início do processo, as principais críticas vinham da União Nacional de Estudantes, que, progressivamente, foram esvaziadas por meio de estratégias articuladas pelo MEC, especialmente quando vinculou o recebimento do diploma à participação dos alunos no processo. Os professores, entretanto, foram sendo atingidos paulatinamente, conforme os cursos foram envolvidos na sistemática. Entre eles, pouco entusiasmo se notava com a proposta de avaliação adotada pelo MEC. Mas também não se fazia sentir um movimento mais orgânico de resistência. É possível localizar uma certa indiferença, que poderia denotar uma suspeição quanto ao sistema de avaliação que progressivamente avançava. $\mathrm{O}$ uso de pares, porém, como uma estratégia de legitimação de que o governo lançou mão para compor as comissões de avaliação e elaboração dos instrumentos, foi minando um olhar mais rigoroso de crítica, pois acessou interesses e estruturas de poder de grupos acadêmicos constituídos.

Essa atitude, pouco a pouco, foi vencida pelas estratégias do MEC, que, invadindo as subjetividades da opinião pública, atingiu, especialmente, a comunidade acadêmica. A publicização dos resultados do "provão" fez com que as instituições de ensino superior, os cursos, os professores e os alunos se mobilizassem no sentido de desencadear medidas que garantissem um desempenho positivo no "provão". O grau obtido, para além dos efeitos formais e legais, passou a expressar uma exteriorização de qualidade, inserindo-se na estratégia de marketing das instituições, reconfigurando suas identidades historicamente constituídas. Ao assumir essa condição, as comunidades universitárias estavam validando o questionável modelo e diminuindo o impacto de suas críticas. Nada foi tão estimulante para a constituição do Estado-avaliador, que tem nas funções de controle da eficiência e produtividade a sua espinha dorsal. Como alerta Popkewitz (1992), na perspectiva neoliberal a avaliação constitui-se numa estratégia do Estado e vem, fundamentalmente, para cumprir suas políticas. O governo brasileiro cumpriu a "lição de casa" determinada pelos órgãos de financiamento internacional, e lançou mão de toda a sua competência e recursos para a implantação e manutenção de um processo de aferição reducionista, distante do sentido pleno da avaliação educacional. Pelo menos, não no sentido que a posição comprometida com a educação cidadã atribui ao termo avaliação.

A compreensão desse panorama impulsionou-me a acompanhar, investigativamente, suas repercussões. Fundamentalmente, meu interesse recaiu na relação entre o modelo tecnicista de avaliação implantado pelo MEC e a reconfiguração da docência na universidade, entendendo que essa política pode ter impactos nos saberes construídos pelos professores. Foram mobilizadas, através do projeto "Formatos avaliativos e concepção de docência", três universidades como território de pesquisa, sendo uma pública e duas particulares, todas no estado do Rio Grande do Sul. Os depoimentos dos professores ajudaram a identificar 
os elementos de realidade e as contradições que essa medida governamental vem provocando.

\section{O que dizem os professores}

Foram ouvidos professores de dez cursos de graduação, utilizando entrevistas intensivas, realizadas pela equipe de pesquisa. Entre esses cursos estavam alguns relacionados às profissões liberais, e outros de licenciatura. Os professores foram instados a falar sobre suas trajetórias acadêmicas e experiências educativas. Essa estratégia mostra-se importante quando se pretende identificar as fontes dos saberes e os contextos em que foram constituídos. Procurava-se, também, dado o objetivo da pesquisa, explorar a percepção dos docentes sobre os processos de avaliação externa, especialmente o "provão".

O discurso de nossos interlocutores sobre sua constituição como professores reforça os achados investigativos contemporâneos: a história de vida, as influências familiares e a trajetória como estudante são constantemente nomeadas como fundamentais na definição da docência como profissão, inclusive para aqueles que escolheram outra graduação como formação inicial. Afirmativas do tipo "minha família era de professores" ou "aprendi a admirar o magistério por causa de minha mãe" foram freqüentes. Outros, mesmo não localizando profissionais da área no território familiar, referiram-se à cultura predominante na casa, dizendo: "meu pai era muito conversador, e sempre achei que o diálogo é muito importante para a construção do conhecimento. Isso me estimulou a ser professor...".

Reforçaram, também, a importância dos saberes da experiência, construídos junto com colegas e, especialmente, com os alunos. Muitos depoimentos revelam a idéia de que "aprendo trocando informações com meus colegas, verificando o que eles estão fazendo na sala de aula, participando com outros colegas de seminários e encontros". Os professores sentem necessidade de afirmar a sua constante preocupação com a atualização, e vão experimentando uma pedagogia da prática que constroem no cotidiano. $\mathrm{O}$ reconhecimento das aprendizagens coletivas, entretanto, não minimiza um sentimento de solidão. Disse um professor de jornalismo que "a docência é uma jornada solitária, pois cada um tem de se haver com seus estudos, incluindo o aprender a ensinar". Nesse sentido, é possível compreender a responsabilização individual que se imputa aos professores e como eles assumem essa condição que, muitas vezes, mascara a compreensão de autonomia, tão acarinhada historicamente. Pimenta e Anastasiou (2002) já haviam chamado a atenção para essa condição dizendo que a "universidade reforça o trabalho solitário, extremamente individual e individualizado; o professor é deixado à sua própria sorte e, se for bastante prudente, evitará situações extremas nas quais fiquem patentes as falhas de seu desempenho" (p. 143). Complementando essa perspectiva, afirmo que o trabalho solitário do professor também protege a sua autoridade científica, que, no imaginário social e do próprio docente, já lhe é atribuída pelo simples fato de ser reconhecido como professor.

Quase numa perspectiva de ensaio e erro, eles atribuem valor às aprendizagens que realizam com seus próprios alunos: "Para mim, o aluno é um termômetro; eles é que me ajudam, com suas perguntas e reações, a ver o que está dando certo". Os professores universitários afirmam que aprendem fazendo, já que, na maioria dos casos, não viveram processos de formação específica para a docência. Reconhecem a necessidade de múltiplos saberes para o exercício da profisssão, mas, ao mesmo tempo, não assumem claramente o discurso da desprofissionalização, decorrente da falta da formação inicial para o magistério. Ainda que suas fragilidades digam respeito principalmente a saberes e competências do campo pedagógico, continuam a reforçar o território do conhecimento específico como o principal esteio de sua docência.

Partindo do pressuposto de que os saberes considerados legítimos são decorrentes da concepção do que seja um bom professor, procurei, durante o processo investigativo, desvendar a percepção de nossos respondentes sobre tal dimensão. Tentando organizar 
os depoimentos, agrupei as respostas em algumas categorias:

a) Saberes relacionados com o conteúdo da matéria de ensino. Essa é uma dimensão muito forte no imaginário dos docentes universitários. No caso das profissões liberais, percebe-se, inclusive, um certo corporativismo, defendendo a exclusividade do conhecimento para um grupo específico de profissionais. A percepção de autoridade está muito presente no discurso dos respondentes, remetida, quase sempre, ao domínio do campo científico especializado. Sugere a obrigatoriedade de um processo de qualificação constante.

b) Saberes relacionados com a prática pedagógica, envolvendo desde o "saber transmitir" até o motivar os alunos e entender como os mesmos aprendem. Inclui a dimensão do prazer de conhecer e de ensinar. Geralmente esse é um saber valorizado no discurso dos professores, que, entretanto, não atribuem a ele uma condição de legitimação acadêmica. Seriam mais tributários de uma tendência, um certo dom que, com a prática, se pode reforçar.

c) Saberes que decorrem de uma postura ética, que torna o professor um educador, na concepção dos nossos interlocutores. Inclui-se aí a condição de saber ouvir, respeitar os alunos, conviver com a diferença, ser justo nas avaliações, ser honesto etc. Atribuem essas características a uma dimensão do caráter dos sujeitos.

d) Saberes próprios das posturas e atividades investigativas, entendidos como aqueles que fazem do professor um produtor do conhecimento. Nesse sentido, incluem a capacidade de formar um aluno crítico e criativo, capaz de continuar aprendendo, numa postura epistemológica emergente. Envolve a capacidade de autocrítica e as atitudes de humildade, dedicação e paciência.
Auscultar o que os professores pensavam sobre uma docência de qualidade, no transcorrer desta pesquisa, representou um parâmetro para a discussão da propriedade da avaliação educativa. Se avaliar é atribuir valor, é preciso que se explicite e discuta o que se constitui em valor, para então se definir o significado da avaliação.

Se forem tomados os depoimentos de nossos respondentes, é possível fazer uma projeção de habilidades e competências necessárias aos professores que envolvem relativa complexidade. Ao mesmo tempo, é possível notar que os saberes que eles afirmam mobilizar estão ligados a uma compreensão de docência que extrapola a dimensão da racionalidade técnica. Incluem capacidades complexas e amplas, envolvendo diferentes perspectivas intelectuais, afetivas, morais e culturais.

Se essa é a projeção de docência de qualidade que fazem os professores, imagina-se que seja, também, a balizadora da sua autocrítica e avaliação. Tudo indica que os professores gostariam de se aproximar desse patamar de desempenho. Nesse sentido, uma avaliação educativa da docência precisaria levar em conta indicadores coerentes com o perfil propositivo.

Certamente a mesma condição estaria presente quando se discutisse o perfil desejado do aluno, ou da proposta curricular que melhor atendesse a perspectiva de qualidade. Tomo aqui a docência como recorte preferencial, porque ela se constituiu no foco da pesquisa desenvolvida, sem, entretanto, deixar de reconhecer outros componentes balizadores de uma avaliação institucional abrangente.

O "provão", certamente, não apresentava as propriedades de um processo de avaliação capaz de se constituir num sistema de avaliação; ele foi apenas um instrumento parcial que media algumas variáveis do processo ensino-aprendizagem. Longe esteve, por exemplo, de abranger as dimensões que os professores referem quando explicitam o que entendem por uma docência de qualidade. Como pode, então, ser legitimado como a expressão da avaliação do ensino superior brasileiro? Que lógica argumentativa sustentou essa possibilidade? 
A resposta a essas questões não encontra argumentos no campo da reflexão epistemológica e axiológica. Os próprios professores entrevistados afirmam que o sistema é frágil, através de expressões como: “o 'provão' é restrito, não diz das condições reais dos alunos...", ou "não acreditamos que essa seja uma boa forma de avaliar...". Não foi localizado nenhum docente que assumisse de forma incondicional a defesa do sistema de avaliação através do "provão". Nem que se posicionasse a seu favor, recorrendo a uma fundamentação consistente, com argumentos pedagógicos e éticos sustentáveis. O que se pode depreender é uma identificação dos docentes com alguns pontos que foram sendo reforçados pela mídia e pela palavra oficial do MEC, especialmente aqueles que usam a possibilidade "de evitar a proliferação de cursos de menor qualificação... que poderiam banalizar o ensino superior". Esse argumento, que tão engenhosamente foi utilizado para convencer a opinião pública sobre o acerto da medida ministerial, encontrou guarida, também, nos docentes. Parece que, atingidos na sua subjetividade, eles perderam a capacidade de uma reflexão política mais ampla e se aliaram a um discurso do senso comum, fabricado dentro de um processo ideológico. Reconhecem, inclusive, que “os resultados do 'provão' repercutem muito nas instituições, pois as notas obtidas servem de propaganda, quer para o bem, quer para o mal”. Poucos dos nossos interlocutores conseguiram fazer uma reflexão mais consistente, estabelecendo conexões entre o que projetavam como docência de qualidade e a aceitação, ainda que parcial, da proposta avaliativa do MEC.

Considerar que os docentes estão atingidos na sua subjetividade é um fato incontestável. Mesmo que eles não admitam, diretamente, uma modificação mais intensa nas suas práticas pedagógicas, percebe-se que foram atingidos de maneira indireta no horizonte de sua ação, aceitando, principalmente, a lógica competitiva como saudável no processo de qualificação universitária. Essa condição mobiliza-nos a entender as palavras de Milton Santos (1998) quando alertava sobre a tirania da informação. E, para o autor, se ela está na mídia, está também no trabalho desenvolvido na universidade, representando uma ameaça para aqueles que têm a tarefa de educar as novas gerações. Advogando numa direção contrária, Milton Santos afirmava que "quanto mais o nosso trabalho for acorrentado, mais estaremos produzindo individualidades débeis. É urgente que o ensino tome consciência dessa situação para esboçar a merecida reação, sem o que corremos o risco de ficar cada vez mais distantes da busca ideal da verdade" (p. 13).

Lamentavelmente, não foi esse o panorama descortinado. Percebeu-se uma análise muitas vezes simplificadora dos efeitos das políticas avaliativas, em que faltava um certo discernimento para compreender a dimensão das propostas, como se depreende dos depoimentos dos docentes. Reconhecem eles que há influências dos resultados nos seus cursos, já que promoveram movimentos de revisão de conteúdos e formas de ensinar. Nesse aspecto, identificam uma contradição, elogiando que, "bem ou mal, o 'provão' fez com que os professores se reunissem para discutir questões ligadas ao ensino", ou afirmando que os docentes "pegam as provas para discutir, e isso teve resultados positivos". Na visão de alguns docentes, "os alunos precisam ser esclarecidos para que o mau desempenho não os coloque em situações menos confortáveis na hora de conseguir um emprego". Afirmativas como essas reforçaram as preocupações sobre o impacto do modelo avaliativo nos docentes e em suas práticas pedagógicas. Enquanto os argumentos ficam na superficialidade, as subjetividades atingidas vão se acorrentando, como expressa Sousa Santos (2000), quer num silenciamento dos verdadeiros significados, quer na inércia de reações.

Como era de se esperar, os cursos que obtiveram uma classificação mais positiva no "provão" são aqueles cujos professores afirmaram menos compromissos com alterações. Os professores festejaram a possibilidade de usufruir desse conforto e declararam continuar o trabalho que já desenvolvem com tranqüilidade. Mencionaram, porém, que "se há alguma preocupação, é a de não baixar a nota". Fica evidente, nessa manifestação, que o imaginário de sucesso 
está levando em conta a explicitação de valor que o resultado do "provão" trouxe. De forma contrária, os professores dos cursos que foram penalizados na classificação afirmaram um maior envolvimento, admitindo formas de pressão, quer dos alunos, quer das instituições a que pertencem.

Nesse particular, as universidades públicas pareceram apresentar menor tensão, compreensível pela relação de trabalho de seus professores. A natureza dos argumentos dos alunos das instituições de ensino superior privadas, quando foram coletados dados entre eles, também indica diferenças em função da filiação da instituição. Quando se sentem atingidos pelo mau desempenho de seus cursos, acusam os professores de não estarem alcançando patamares positivos no ensino. Evidencia-se um certo processo de autofagia pedagógica, no qual professores e alunos tendem a se culpabilizar mutuamente, enquanto o Estado lava as mãos, tanto das responsabilidades sobre a lógica avaliativa quanto da sua função de zelar pelo processo educacional. Essa atitude torna os professores das universidades privadas mais fragilizados e alvo de punições, além de aumentar a possibilidade de desemprego. Certamente esses docentes formaram o grupo mais atingido pela política adotada, que favoreceu a reconfiguração de sua docência, principalmente porque o que está em jogo é a noção de autoridade dentro de uma estrutura de poder.

O professor, historicamente, preservou a idéia de autoridade como parte da função que a sociedade lhe destinava. Na maior parte das vezes, a noção de autoridade estava alicerçada numa condição diferenciadora que o acúmulo de conhecimentos propiciava. O professor, sendo aquele que sabe, poderia exercer autoridade sobre os que não sabem e, em muitos casos, essa relação redundava em autoritarismo. Entretanto, é interessante analisar a perspectiva de Correia e Matos (2002) sobre essa questão. Os autores chamam a atenção para a constatação de que

a noção de autoridade pode distinguir-se da noção de poder pelo fato de, em sintonia com sua raiz etimológica, o seu significado estar associado à noção de autor, isto é, à idéia de criador, de alguém que está na origem da própria ação e que é capaz de se autorizar, ao passo que a palavra poder nos remete mais para a idéia de procuração, de mandato, de ter influência e força. (p. 30)

A fragilidade em que se situa o professor no contexto do processo educativo de cunho concorrencial é identificada com facilidade. Quando a educação passa a ser tomada como mercadoria e objeto de troca de bens materiais e simbólicos, os alunos são nomeados como clientes, no mais puro estilo empresarial. Pagam eles, direta ou indiretamente, por um bem, e exigir um certificado de qualidade faz parte da negociação. O selo de $\mathrm{ISO}^{2}$ deve estar gravado no produto!

É patente o descompasso que acarreta essa percepção, na qual há uma linearidade entre competências do professor e desempenho dos alunos. Desconsideram-se os demais fatores que interferem na formação dos estudantes, tais como suas condições de ingresso, contexto cultural, possibilidades de dedicação, dupla jornada etc.

Mas o mais grave de tudo é que o padrão de qualidade pouco é discutido e a culpabilidade do professor se afirma sobre um perfil docente, que quase não tem a ver com o conceito de autoridade tomado neste estudo, o qual tem como central a condição de autoria, referindo-se ao protagonismo do docente em suas práticas e concepções. Sendo o padrão de qualidade definido em condições exógenas e distantes do contexto cultural em que atuam os atores pedagógicos, priva-se, progressivamente, o professor, e também os seus alunos, de assumir a autoria de suas próprias trajetórias. E, por viverem a crise da autoridade, esses professores têm fragilizadas as suas condições de poder.

Correia e Matos (2002, p. 31) afirmam ainda que o poder dos professores se apóia num tripé: uma de-

\footnotetext{
2 A International Standardization for Organization (ISO) é
} uma organização não-governamental sediada em Genebra em 1947, com o objetivo de ser um fórum mundial de normalização de padrões de qualidade. Em geral é aplicada a sistemas de gestão empresarial ou industrial. 
legação cognitiva, uma delegação política e uma delegação jurídica:

no plano cognitivo, o professor se define como um delegado de um saber científico do qual é o fiel depositário; por sua vez, no plano político e social, o professor é depositário de um fiel poder cultural, público e laico, delegado pelo Estado-Nação ou por uma geração social; finalmente, o poder do professor apóia-se numa delegação de ordem jurídica que, assente nos mandatos cognitivos e políticos, legitima o exercício da capacidade de julgar, emitir uma sentença ou de proceder a uma avaliação que, pelo menos nos níveis mais elevados dos sistemas educativos, não é suscetível de recurso quanto ao seu conteúdo.

Esse tripé em que se alicerça, historicamente, o poder dos professores vem sendo atingido na sua legitimidade e reconhecimento. A lógica do modelo avaliativo que se vinha praticando nos sistemas educativos do mundo ocidental e, especialmente, no Brasil, coloca em suspeita a delegação cognitiva, bem como a cultural e a de ordem jurídica. Significa que cada vez mais o professor decide menos sobre seu ofício. E, à medida que avança a desresponsabilização pelas decisões que toma, o docente sente-se mais distante do compromisso com o ato educativo. Silencia sobre essa dimensão e sente que a lógica da produtividade exógena é reforçada, que, ao fim e ao cabo, é a que lhe rende reconhecimento.

Vê-se, então, que os professores universitários, atualmente, no Brasil, estão submetidos progressivamente à lógica concorrencial, estimulada pelos modelos externos de avaliação, e são, também, fortemente atingidos na sua condição de poder, tal qual já o foram na sua autoridade.

Os depoimentos de nossos respondentes contêm indicativos dessa situação. Tomando a classificação de Correia e Matos (2002), pode-se perceber que, no plano cognitivo, manifestam uma certa inconformidade com a proposta avaliativa, mas, ao mesmo tempo, assumem a possibilidade de submissão aos padrões propostos. Disse um deles: "nunca modifiquei nada devido aos resultados do 'provão'; não acho isso bom, apesar de pegar as provas para ver os equívocos [...] mas eu acho que os professores têm de ser fiscalizados [...] o professor não é o dono do saber". Louvável a percepção de que o professor não é o dono do saber, se essa fosse uma postura reflexiva de democratização das relações pedagógicas. Preocupante é a afirmativa da necessidade de fiscalização, sem ao menos fazer um comentário do sentido dessa palavra incorporada ao seu discurso. A fiscalização do cumprimento dos programas nem sempre se coaduna com as reais necessidades dos estudantes, estando, não raro, a serviço da lógica burocratizada da eficiência.

No plano político e social há, também, uma evidente desvalorização do professor. Ele não mais é reconhecido como capaz de honrar a confiança da sociedade para a educação de seus jovens e crianças. $\mathrm{O}$ docente começa a ser visto como "um investimento" que merece a atenção do empregador, desde que tenha um perfil que atenda às exigências da luta concorrencial. Torna-se, também, descartável quando isso não acontece. Pode-se exemplificar essa condição pelo depoimento de um dos nossos respondentes, que afirmou: "fico preocupado pensando no que aconteceria caso não tivéssemos tirado um $\mathrm{A}$ no 'provão' [...] como justificar esse comportamento frente a nossa instituição? [...] Para ela interessa que os cursos sejam bem qualificados; isso é marketing!".

Usando como apoio teórico a classificação de Correia e Matos (2002), compreende-se, finalmente, que a delegação jurídica também pode ser atingida no contexto da educação concorrencial. Os professores não são mais reconhecidos como as autoridades que avalizam sobre a preparação de seus alunos. Os critérios de exigência propostos pelos docentes na instituição universitária perdem a legitimidade, o que os coloca em permanente suspeita de uma ação pouco rigorosa. Há uma evidente crise de poder, na qual o arbítrio do professor é substituído pelo arbítrio do Estado. Este configura-se como o parâmetro regulatório, quer enquanto prova única aplicada a todos os estudantes do país, quer quando inspira a docência universitária, como afirma um professor: "o 'provão' é um lugar onde me apoio para tomar deter- 
minadas decisões, ou seja, onde devo dar mais ou menos ênfase. Eu até nem sei se isso é uma coisa boa ou não; mas daqui a pouco, em certo sentido, serei julgado, e não custa estar preparado para esse julgamento...".

Esse depoimento fortalece a evidência de que os docentes estão sofrendo fortes influências do modelo avaliativo. Ao enfatizar conteúdos considerados válidos, o processo traz, como efeito secundário, mas não menos importante, "a condição de marginalização dos campos e dos saberes não avaliados" (Estevão, 2001, p. 171). A tendência é que haja um enfraquecimento dos campos de conhecimento que não são privilegiados pelo instrumento de avaliação, com visíveis prejuízos para a formação acadêmica. Mesmo no plano cognitivo, é possível divergir do recorte de inclusão, que os avaliadores selecionam a partir de um arbitrário não justificado. Se for tomado, então, o plano das habilidades e compromissos, amplia-se o espectro da exclusão, com mais propensão a silenciar objetivos até agora entendidos como essenciais. Atingidos na sua subjetividade por essa gama de influências, os professores tendem a reorganizar seus esquemas cognitivos e valorativos na construção da docência.

\section{O que estão aprendendo os professores?}

Tomando o referencial de Tardif $(2001,2002)$ e Tardif e Raymond (2000) para analisar os saberes que constituem a profissão docente, percebe-se que há fontes diversas que inspiram as escolhas dos professores para configurar o cotidiano de seu trabalho. Os autores afirmam que os saberes da docência são plurais e heterogêneos, portanto, oriundos de diferentes fontes e processos. Entre eles, citam a história cultural dos sujeitos na escola como uma inspiração de grande importância. Essa perspectiva aproxima-se do conceito de cultura experiencial de Peréz Gómez (1998). Para esse autor, a cultura experiencial trata da peculiar configuração de significados e comportamentos que os sujeitos elaboram de forma particular. Principalmente quando são induzidos pelo contexto, em sua vida prévia e paralela à escola, por meio dos intercâmbios com o meio familiar e social que rodeiam a sua existência, ainda que mediados por sua experiência biográfica e sua trajetória pessoal. A cultura experiencial de professores e estudantes serve de base principal para a construção da identidade institucional, afirma Peréz Gómez. Outros estudos têm reforçado essa perspectiva (Cunha, 1989; Pimenta \& Anastasiou, 2002) e, sendo frutos de pesquisa, atestam o fato de os professores recorrerem às suas experiências como estudantes para tomar decisões sobre a forma como ensinam.

Recuperando a concepção epistemológica que assume a subjetividade e a experiência como fonte insubstituível de aprendizagem, Tardif (2002) dá especial relevo, também, às aprendizagens que o professor realiza no ambiente de trabalho, a partir da sua inserção profisssional. $\mathrm{O}$ autor analisa ainda a relação entre o trabalho do professor e seu objeto de trabalho, que é, fundamentalmente, o aluno, tanto na sua dimensão individual como grupal, e o processo ensinoaprendizagem. Dada essa condição, as relações que o professor estabelece com seu trabalho são de natureza humana, sujeitas a interferências valorativas e construídas num contexto de complexibilidade. Nesse sentido, é inadequado pensar que o professor tem controle direto sobre seu objeto de trabalho, como acontece em outros campos profissionais. "Nada nem ninguém pode forçar um aluno a aprender se ele mesmo não se empenhar no processo de aprendizagem [...] pois os alunos sofrem inúmeras influências que podem afetar seu rendimento escolar" (idem, p. 132).

Fazendo uma analogia com o trabalho industrial, Tardif (2002) ressalta que, para este, há uma relação direta entre processo e produto; já na docência, o produto do ensino é de grande intangibilidade, pois diz respeito, principalmente, a atributos humanos e sociais que, por sua natureza, são de difícil mensuração. Reduzi-los a uma quantificação e, mais grave ainda, a uma única prova, é desconhecer e desqualificar a docência no sentido educativo. Certamente, com a pressão de modelos de avaliação do tipo do "provão", os professores tendem a valorizar aprendizagens diretamente relacionadas com os produtos, correndo o 
risco de atribuir à educação um caráter neotecnicista, pois ficam preocupados com resultados que alcancem significados no mundo produção. Como afirma Dias Sobrinho (2000), "os exames gerais têm a sua motivação mais fora do que dentro da escola; apresentam uma racionalidade muito mais mercadológica e governamental que pedagógica; valorizam muito mais a competitividade do que a solidariedade" (p. 160). Exercem uma forma de coerção simbólica sobre os professores e alunos, que tendem a silenciar os esforços educativos que não se ajustam aos critérios paradigmáticos da produtividade.

Outra dimensão que pode afetar profundamente os saberes dos professores está ligada ao reforço da condição de visão única, tão cara à ciência moderna e agora reforçada pelos dispositivos políticos da produtividade. Trata-se de um processo de padronização, como se houvesse uma única forma de conhecimento e uma só alternativa de formação. Como lembra Sousa Santos (2000), o dilema consiste em que a validação de uma só forma de conhecimento provoca a cegueira epistemológica e valorativa, destruindo as relações entre os objetos e, nessa trajetória, eliminando as demais formas alternativas de conhecimentos: "O reverso da força da visão única é a incapacidade para reconhecer visões alternativas" (p. 241). O autor, sabiamente, alerta que esse fenômeno pode redundar num epistemicídio, afirmando que "a destruição de formas alternativas de conhecimento não é um artefato sem conseqüências, antes implica a destruição de práticas sociais e desqualificação de agentes sociais que operam de acordo com o conhecimento em causa" (idem, p. 242).

Diante desse quadro, é fácil perceber que os esforços que marcaram o início de uma ruptura epistemológica no campo da educação superior estiveram seriamente ameaçados. Ainda frágeis e minoritários, eles procuravam afirmar-se no campo acadêmico, com toda a dificuldade decorrente da presença paradigmática dominante. Já na sua geração, carregavam o ônus da complexidade da iniciativa. Sousa Santos (2000) afirma que "a luta paradigmática é, no seu conjunto, altamente arriscada" (p. 344), pois exige uma subje- tividade emergente que envolve ruptura epistemológica e societal. Para o autor, "formas alternativas de conhecimento geram práticas alternativas e vice-versa" (idem, ibidem), perpassando o conceito de subjetividade, que se constitui como o grande mediador entre conhecimento e práticas.

As inovações que se adivinhavam próximas materializavam-se pelo reconhecimento de formas alternativas de saberes e experiências, nos quais se imbricavam objetividade e subjetividade, senso comum e ciência, teoria e prática, cultura e natureza, anulando dicotomias e procurando gerar novos conhecimentos através de novas práticas.

Essas inovações, entendidas como ruptura paradigmática, exigem dos professores uma reconfiguração de saberes, e favoreciam o reconhecimento de que era preciso trabalhar no sentido de transformar, como lembra Sousa Santos (2000, p. 346), "transformando 'inquietude' em energia emancipatória”. Envolviam o reconhecimento da diferença e implicavam, em grande medida, um trabalho que consiste, especialmente, em gerir relações sociais com seus alunos. No dizer de Tardif (2002, p. 132), “é por isso que a pedagogia é feita de dilemas e tensões, de negociações e estratégias de interação". Para o autor, "ensinar é fazer escolhas, constantemente, em plena interação com os alunos" (idem, ibidem). Essas escolhas são dependentes da experiência dos atores, do contexto de tempo e território do ensino, das convicções e crenças que suportam o trabalho e, conseqüentemente, de situações que, sendo únicas, exigem respostas diferenciadas.

Se não houve muito tempo para consolidar trajetórias, são exemplos próximos de nós as experiências de ensino e aprendizagem relatadas por Pimentel (1992), Cunha (1998), Lucarelli (2002), Leite (1997) e Fernandes (1999, 2001), entre outras analisadas em forma de pesquisa. Foram elas gestadas no bojo de momentos históricos favorecedores de esperança, quando se acreditava na avaliação como um valor para os próprios sujeitos que dela participavam, e que exigia saberes relacionados com a partilha analítica das situações educativas. 
Como, então, agir ante o modelo político que impõe, num retrocesso histórico, a homogeneização como paradigma? Que saberes precisam ser mobilizados nos professores para que a visão crítica dos processos regulatórios redunde em movimentos de resistência, em diferentes campos e manifestações? Como tomar essa realidade como ponto de referência para uma discussão mais sistematizada no interior da universidade? Como os processos de formação de professores estão enfrentando a problemática de uma avaliação regulatória? Há espaços para a continuidade de iniciativas emancipatórias, contra a corrente dominante?

A pesquisa desenvolvida com os professores teve o intuito de ser um agente analítico de compreensão das políticas educativas, mas, também, uma forma de concentrar energias para a resistência. Quis alinharse a outros movimentos que reforcem a afirmativa de Sousa Santos (2000) de que a subjetividade emergente é uma subjetividade do sul. Ao fazer essa afirmativa, o autor recupera analogicamente a idéia eurocêntrica, contrapondo-se ao entendimento de que o rumo certo está no norte, de onde vem o uso corriqueiro do termo "nortear" como sinônimo de colocar no prumo, dar um sentido adequado. Reconhecer o sul como energia inovadora é estar disposto a legitimar formas alternativas de conhecimento, bem como ousar andar na subjetividade da fronteira.

Na transição paradigmática, diz Sousa Santos (2000, p. 355):

subjetividade navega por cabotagem, guiando-se hora pelo paradigma dominante, ora pelo paradigma emergente. E, se é verdade que o seu objetivo último é aproximar-se tanto quanto possível do paradigma emergente, ele sabe que só ziguezagueando lá poderá chegar e que, mais do que uma vez, será o paradigma dominante a continuar a guiálo. Cabotando assim, ao longo da transição paradigmática, a subjetividade de fronteira sabe que navega num vazio cujo significado é preenchido, pedaço a pedaço, pelos limites que ela vai vislumbrando, ora próximos, ora longínquos.

Nessa perspectiva, foi possível acreditar na condição de ruptura com a lógica avaliativa dominante que, sendo aplicada ao longo do tempo, encontrou um terreno fértil para seu revigoramento nos últimos anos, ante a reconfiguração da concepção de Estado no mundo ocidental. Essa condição, entretanto, exigiu uma tessitura paciente de esforços e energias que envolvem a condição de escuta e a condição de espera, sem entretanto, abrir mão da condição de análise crítica e reflexiva, que vem ajudando a compreensão dos acontecimentos e das teias que os envolvem.

Anima perceber que as pessoas em geral, e os professores particularmente, são capazes de viver nos limites, submetidos à lógica dominante da avaliação, mas navegando na fronteira das práticas que ficam às margens. Talvez daí possa sair uma explicação para seus silêncios. Quem sabe são eles uma possibilidade de esperança.

A condição da esperança, assim como a da resistência, não produz efeitos instantâneos e lineares. Mas elas anunciam novas possibilidades e apostam na perspectiva da possibilidade. Provavelmente, foram as reflexões sobre os discursos oficiais e institucionais e os silêncios produzidos nas frestas dessa realidade que favoreceram a mudança da política de avaliação institucional adotada pelo Estado brasileiro a partir da lei n. 10.861, de 14 de abril de 2004, que criou o Sistema Nacional de Avaliação da Educação Superior (SINAES). Traz ele, nos seus princípios e pressupostos, as idéias centrais da integração, da articulação e da participação (Brasil, 2004), indicando um afastamento da perspectiva de visão única e universal da qualidade assumida pelo mecanismo anterior, formalizado pelo "provão". Retoma a auto-avaliação como dimensão formativa e pedagógica do processo avaliativo e assume que "o objetivo central do processo avaliativo é promover a realização autônoma do projeto institucional, de modo a garantir a qualidade acadêmica no ensino, na pesquisa, na extensão, na gestão e no cumprimento de sua pertinência e responsabilidade social" (idem, p. 10).

Poderá essa política avaliativa se consolidar numa perspectiva coletiva? Alcançará seus objetivos, mesmo convivendo com os espaços de contradição presentes na sociedade nacional e global? Terá 
forças suficientes para favorecer uma identidade institucional condizente com seus pressupostos? Provocará nos docentes uma cultura experiencial que avance na perspectiva da necessária ruptura com as práticas tradicionais de ensinar e aprender? Sobreviverá ao imperativo classificatório do mercado e da lógica concorrencial?

Provavelmente, será a pesquisa, mais uma vez, que poderá favorecer a compreensão dos processos e trajetórias a percorrer daqui para diante. Não se trata de tarefa simples. Mas alimenta a esperança de novas possibilidades, mostrando que resistir é possível, e que tem sentido acreditar na mudança.

\section{Referências bibliográficas}

BORJA, Rodrigo. Educación, globalización y sociedad del conocimiento. In: BROVETTO, Jorge; MIX, Miguel; PANIZZI, Wrana (Orgs.). A educação superior frente a Davos. Porto Alegre: Ed. da Universidade, Porto Alegre, 2003. p. 34-77.

BRASIL. Ministério da Educação. Diretrizes para a avaliação das instituições de educação superior. Brasília, DF: MEC/Comissão Nacional de Avaliação da Educação Superior (CONAES), 2004. CORREIA, João Alberto; MATOS, Manuel. Solidões e solidariedades nos quotidianos dos professores. Porto: Ed. ASA, 2002.

CUNHA, Maria Isabel da. O bom professor e sua prática. Campinas: Papirus, 1989.

.O professor na transição de paradigmas. Araraquara:

JM Editores, 1998.

DIAS SOBRINHO, José. Avaliação da educação superior. Petrópolis: Vozes, 2000.

Universidade e avaliação. Entre a ética e o merca-

do. Florianópolis: Insular, 2001.

ESTEVÃO, Carlos. Políticas avaliativas, autonomia e avaliação. Reflexões em torno da dialética do reajustamento da justiça e da modernização. Revista Portuguesa de Educação, Braga: Serviço de Publicações do Instituto de Educação e Psicologia da Universidade do Minho, v. 14, n. 2, p. 155-178, 2001.

FERNANDES, Cleoni Maria B. Sala de aula universitária: ruptura, memória educativa, territorialidade - o desafio da construção pedagógica do conhecimento. Tese (Doutorado em Educação) Faculdade de Educação, Universidade Federal do Rio Grande do Sul, 1999.
(Org.). Educação superior. Travessias e atravessamentos. Canoas: Ed. da Universidade Luterana do Brasil, 2001.

FREIRE, Paulo. Ação cultural para a liberdade. Rio de Janeiro: Paz e Terra, 1976.

HOUSE, Ernest R. Evaluación, ética e poder. 2. ed. Madri: Morata, 1997.

LARROSA, Jorge. Pedagogia profana. Danças, piruetas e mascaradas. Porto Alegre: Contrabando, 1998.

LEITE, Denise. Universidade futurante. Campinas: Papirus, 1997. LUCARELLI, Elisa. O assessor pedagógico na universidade: novas propostas para uma didática universitária. In: FERREIRA, Naura; AGUIAR, Marcia Angela (Orgs.) Para onde vão a orientação e a supervisão educacional? Campinas: Papirus, 2002. p. 123-148.

LÜDKE, Menga; MOREIRA, Antônio Flávio. Propostas recentes para a reforma da formação de professores no Brasil. Revista Portuguesa de Educação, Braga: Serviço de Publicações do Instituto de Educação e Psicologia da Universidade do Minho, v. 15, n. 1, p. $58-83,2002$.

MARTINS, Ângela Maria. Autonomia e descentralização: a (ex)tensão do tema na agenda das políticas educacionais recentes. Revista Portuguesa de Educação, Braga: Serviço de Publicações do Instituto de Educação e Psicologia da Universidade do Minho, v. 15, n. 1, p. 269-296, 2002.

PERÉZ GÓMEZ, Ángel Ignacio. La cultura escolar en la sociedad neoliberal. Madri: Ediciones Morata, 1998.

PIMENTA, Selma; ANASTASIOU, Lea. Docência no ensino superior. São Paulo: Cortez, 2002.

PIMENTEL, Maria da Glória. O professor em construção. Campinas: Papirus, 1992.

POPKEWITZ, Thomas. Algunos problemas y problemáticas en la producción de la evaluación. Revista de Educación, Madri, n. 299, p. 95-118, 1992.

REMEDI, Alione E. La institución: un entrecruzamiento de textos. In: REMEDI, Alione E. (Coord.). Instituciones educativas: sujetos, historias e identidades. México: Plaza y Valdés, 2004. p. $48-59$.

SANTOS, Milton. O professor como intelectual na sociedade contemporânea. In: ENCONTRO NACIONAL DE DIDÁTICA E PRÁTICA DE ENSINO (ENDIPE), 9., 1998, Águas de São Pedro. Anais... São Paulo: ENDIPE, 1998, v. 3. p. 14-21.

SOUSA SANTOS, Boaventura de. A crítica da razão indolente. Contra o desperdício da experiência. São Paulo: Cortez, 2000. 
TARDIF, Maurice. O trabalho docente, a pedagogia e o ensino: interações humanas, tecnologia e dilemas. Cadernos de Educação, Faculdade de Educação da Universidade Federal de Pelotas, ano 10, n. 16, p. 7-14, jan./jun. 2001.

. Saberes docentes e formação profissional. Petrópolis:

Vozes, 2002.

TARDIF, Maurice; RAYMOND, Danielle. Saberes, tempo e aprendizagem do trabalho no magistério. Educação e Sociedade, v. 21, n. 73 , p. 209-244, dez. 2000.

MARIA ISABEL DA CUNHA, doutora em educação pela Universidade Estadual de Campinas (UNICAMP) e professora aposentada da Faculdade de Educação da Universidade Federal de Pelotas (UFPel), é professora do Programa de Pós-Graduação em
Educação da Universidade do Vale dos Sinos (UNISINOS) e dedica-se à formação de professores, especialmente à relação da docência universitária com a didática e a prática pedagógica. Publicações mais relevantes: O bom professor e sua prática (Campinas: Papirus, 1989, atualmente em 17. ed.), O professor universitário na transição de paradigmas (Araraquara: JM Editora, 1998) e Políticas públicas e docência na universidade: novas configurações e possíveis alternativas (Revista Portuguesa de Educação, Braga: Serviço de Publicações do Instituto de Educação e Psicologia da Universidade do Minho, v. 16, n. 2, p. 45-68, 2003). E-mail: cunhami@uol.com.br

Recebido em novembro de 2004 Aprovado em junho de 2005 
de Brasil (Sudeste, Sur, Centroeste y

Noreste) en el período 2001-2004. Las principales acciones son investigadas teniendo como ejes analíticos el conjunto de percepciones sobre juventud que anclan las iniciativas y las formas que son propuestas por el Poder Público para la interacción con los segmentos juveniles.

Palabras claves: juventud; políticas públicas; poder local

Maria Isabel da Cunha

Docência na universidade, cultura e avaliação institucional: saberes silenciados em questão

Apresenta os resultados de pesquisa interinstitucional sobre o Exame Nacional de Cursos, conhecido como "provão", na qual foram entrevistados alunos, coordenadores e professores de doze cursos de graduação, pertencentes a instituições de ensino superior do estado do Rio Grande do Sul. Os resultados detectaram elementos de impacto das políticas avaliativas sobre as formas de atuação dos professores. Houve, entretanto, variação de resultados, de acordo com a natureza dos cursos. Nos cursos que preparam para profissões liberais a lógica concorrencial foi mais presente e nas licenciaturas houve uma centralidade nos processos pedagógicos. Ambos, entretanto, foram atingidos nas suas subjetividades e tendem a reorganizar suas práticas segundo o parâmetro de sucesso imposto pelo modelo avaliativo. Interferem nos saberes docentes, silenciando muitos daqueles que se contrapõem ao padrão imposto pela avaliação, direcionando a qualidade da prática pedagógica universitária.

Palavras-chave: políticas de avaliação; pedagogia universitária; saberes docentes

Teaching in higher education, culture and institutional evaluation: the matter of silenced knowledge
The paper reports results from an interinstitutional research on the Brazilian National Course Exam. Students, teachers and coordinators belonging to 12 higher education courses from different institutions at the state of Rio Grande do Sul were interviewed. Results detected the impact of evaluation policies on the performance of teachers. There were, nevertheless, some variety among the results, when different courses were concerned. Courses focusing on liberal professions showed a competitive approach while those focusing on teacher training programmes were more centered on pedagogical processes. Nonetheless, both profiles were hit on their subjectivity and showed a tendency to reorganization towards the success parameters imposed by the evaluation model. The model interferes with teachers knowledge and silences many of those contra posing the patterns imposed by the evaluation, directing the quality of pedagogical practice at the universities.

Key-words: evaluation policies; pedagogical university; knowledge teachers

Docencia en la universidad, cultura y validez institucional: saberes silenciados en cuestión

Presenta los resultados de encuesta interinstitucional sobre el Examen $\mathrm{Na}$ cional de Cursos, conocido como "provão", en la cual fueron entrevistados alunos, coordenadores y profesores de doce cursos de graduación pertenecientes a instituciones de enseñanza superior del estado de Rio Grande del Sur. Los resultados detectaron elementos de impacto de las políticas evaluativas sobre las formas de actuación de los profesores. Hubo, entretanto, variación de resultados, de acuerdo con la naturaleza de los cursos. En los cursos que preparan para profesiones liberales la lógica concurrencia fue más presente y en las licenciaturas hubo una centralidad en los procesos pedagógicos. Ambos, entre tanto, fueron alcanzados en sus objetividades y tienden a reorganizar sus prácticas según el parámetro de suceso impuesto por el modelo evaluativo. Interfieren en los saberes docentes, silenciando muchos de aquellos que se contraponen al padrón impuesto por la evaluación, direccionando la cualidad de la práctica pedagógica universitaria.

Palabras claves: politicas de evaluación; pedagogía universitaria; saberes docentes

Danilo R. Streck

A educação popular e a (re)construção do público. Há fogo sob as brasas?

O artigo busca situar a educação popular no contexto da reconstrução da esfera pública na América Latina. A partir da volta às suas origens para identificar o lugar social e os espaços pedagógicos nos quais a educação popular se originou, argumenta que um traço distintivo dela é a própria busca, no mesmo sentido em que a identidade latino-americana se constitui como esse lugar de possibilidades. Analisa a seguir algumas estratégias pedagógicas clandestinas, assim entendidas por se caracterizarem como ausência ou ocultamento, respectivamente: pedagogia da sobrevivência, da resistência e da relação. No final, retorna à imagem do labirinto para definir as perplexidades - históricas e atuais - da educação popular.

Palavras-chave: educação popular; América Latina; esfera pública; pedagogias alternativas

\section{Popular education and the} (re)construction of the public sphere. Is there fire in the embers?

The main purpose of this article is to situate popular education within the 